\title{
El Ecologismo de los pobres
}

María Camila Mejía

\author{
Luisa Fernanda Rengifo \\ (luisananda92@hotmail.com)
}

MARTÍNEZ ALIER, Joan (2009). El Ecologismo de los pobres. Barcelona, España. Editorial Icaria, 395 pp.

La presente reseña está basada en el libro publicado por Joan Martínez Alier en el 2009, El ecologismo de los pobres. Su autor es un economista español que ha desempeñado un papel protagónico en asociaciones relacionadas con el medio ambiente, ha tenido experiencia como escritor e investigador y es pionero en temas como la ecología económica, la política ecológica y la ecología de los pobres.

A lo largo de esta obra, el autor explica las tres corrientes del ecologismo: el culto de la vida silvestre; el evangelio de la eco-eficiencia; y, el ecologismo de los pobres. No obstante, se concentra en la más reciente de las tres, el ecologismo popular. Ahora bien, para facilitar el entendimiento de aquella corriente, Martínez Alier se sirve de los movimientos de la economía ecológica y la ecología política; además, presenta casos que muestran el auge de la ecología de los pobres. Para lograrlo, divide su obra en once capítulos. En el primero, se introducen las tres corrientes del ecologismo, la primera se denomina el culto de la vida silvestre, que consiste en preservar la naturaleza sin ninguna interferencia humana; ésta es indiferente al crecimiento económico. La segunda corriente es el Evangelio de la eco-eficiencia, que se preocupa por el manejo sustentable de los recursos naturales, cree en el desarrollo sostenible y la modernización ecológica, y tiene en cuenta el control de la contaminación. La tercera corriente es la Justicia Ambiental y el Ecologismo de 
los pobres, tema central de libro. Con esta se busca preservar la naturaleza puesto que es la fuente del sustento de diferentes comunidades (por lo general rurales) alrededor del mundo.

En los capítulos dos y tres, Martínez Alier, explica de manera amplia y detallada la economía ecológica. Esta proporciona una visión sistémica de las relaciones entre la economía y el medio ambiente, es decir, estudia el enfrentamiento entre la evolución de la economía y el medio ambiente. Para facilitar su estudio, el autor emplea índices de insustentabilidad para juzgar el impacto de la economía humana en el medio ambiente, entre ellos está la huella ecológica, el coste energético, el uso de materiales, entre otros.

El capítulo cuatro contiene la definición de ecología política que Martínez Alier propone. Ésta estudia los conflictos ecológicos distributivos, es decir la forma en que se distribuye el acceso a los beneficios que se obtienen de los recursos naturales y a los servicios proporcionados por el ambiente como un sistema de soporte de vida.

A partir del capítulo cinco, Martínez Alier muestra casos aplicados de la mala distribución de los recursos, contamina- ción al medio ambiente y el impacto que tienen los avances económicos a las comunidades. En el presente capitulo, se ve el conflicto entre los manglares y las camaroneras, cómo el crecimiento en el consumo de este marisco ha afectado a diferentes comunidades que tienen su sustento de vida a través de los manglares, que son destruidos para la producción en masa de los camarones. Sin embargo, se muestran las diferentes acciones que han realizado las comunidades junto a unas ONG para reclamar el derecho a una mejor distribución del territorio y que los manglares sean devueltos a su estado natural.

Posteriormente, en el capítulo seis, el autor presenta diferentes historias de extracción de recursos como el oro y petróleo; también de la tala de árboles y contaminación de ríos. Estas son usadas por Martínez Alier para reiterar los conflictos socioambientales que se presentan en diferentes poblaciones del mundo, donde el común denominador es la violación de los derechos humanos de los habitantes, a quienes se les invaden sus territorios y se les despoja de todo los recursos, las costumbres a las que se han habituado y se les priva de la libertad de expresión. Sumado a los conflic- 
tos ya mencionados, el autor desarrolla el concepto de biopiratería, donde una vez más se presenta la apropiación de recursos sin dar reconocimiento de propiedad a los campesinos o indígenas que son quienes realmente conocen las ventajas que les brinda la naturaleza. Como reacción a dichos conflictos se presentan varios grupos o asociaciones que deciden luchar por defender poblaciones vulnerables. Sin embargo, los resultados obtenidos en la mayoría de estos son poco alentadores, pues siempre predomina el interés de los más poderosos a nivel económico.

"Un mundo en el cual la urbanización crece es, por consiguiente, un mundo más insustentable”, es una frase que resume de forma general lo que Martínez Alier describe en el capítulo siete: Los indicadores de insustentabilidad como indicadores de conflicto social. Se introducen el consumo de agua per cápita, la producción de gases del efecto invernadero, el uso por persona de energía para transportarse, etc. Además, el autor discute aspectos a tener en cuenta para determinar el grado de sustentabilidad. Entre ellos, el grado de urbanización de la población mundial y el gado de organización y planeación del desarrollo de las ciudades. Para soportar los argumentos desarrollados presenta el desplazamiento de los conflictos ecológicos en las ciudades europeas. También presenta las luchas contra la contaminación en India y establece las posibles diferencias existentes entre espacios habitados por gente pobre rica y los pobres.

Más adelante, en el capítulo ocho se explica el surgimiento del concepto de Justicia Ambiental como reacción al racismo ambiental predominante en Estados Unidos. Sin embargo, con el paso del tiempo se empieza a extender a Sudáfrica y a Brasil. También, se habla de una muy probable expansión del término a nivel mundial, teniendo en cuenta que existen muchos conflictos que generan desigualdad en el aprovechamiento de los recursos (desplazamiento de poblaciones por construcción de represas, luchas por la preservación de los manglares, contaminación de ríos, etc.). Adicionalmente, el autor hace énfasis en la falta de inclusión de "gente de color" en cuerpos directivos de las entidades reguladoras de temas relacionados con el medio ambiente. Asimismo, se plantean preguntas de reflexión donde se cuestiona la razón de 
los hechos anteriormente mencionados y cómo se puede mejorar o manejar los riesgos medioambientales a los que se exponen grupos afroamericanos, latinos e indígenas.

En el capítulo nueve se describe el papel que toma el estado y los diferentes actores involucrados en los conflictos y cómo cada uno de estos responde al movimiento de justicia ambiental. El autor propone que el Estado es el principal responsable de la existencia de compañías que generan conflictos ambientales (energía nuclear, represas, oleoductos, etc). Sin embargo, más adelante aclara que con el paso del tiempo y la aparición de los movimientos ambientales se pretende compartir la responsabilidad y aumentar la participación de estos en el establecimiento de políticas para defender el entorno y los afectados.

Otro tema que destaca Martínez Alier en el capítulo es la relación entre el género y el medio ambiente. Aquí surge un punto común con algunos comentarios discutidos en clase. Las familias indígenas y campesinas que son las que generalmente habitan las zonas rurales de Colombia y que son las más afectadas con el conflicto socioambiental, tienen un pensamiento bastante tradicio- nal. Generación tras generación se van transfiriendo las costumbres de forma de vida. En estas, se destaca la labor que hace la mujer como ama de casa. Por ende, es la encargada de la recolección de agua y alimentos para la subsistencia de la familia. Al tener mayor contacto con la naturaleza y entender y apreciar la importancia de estos recursos para sus vidas, tienen mayor conciencia del cuidado de su entorno. Por este motivo, son las mujeres quienes han tenido un papel determinante en el Ecologismo de los Pobres, pues son ellas quienes han asumido el liderazgo para defender su territorio y se han enfrentado en conflictos violentos para luchar por los derechos que son violados por multinacionales u otros actores.

En el capítulo diez, Martínez Alier establece las causas del surgimiento de una deuda ecológica y lo define con un término económico. Este concepto aparece como consecuencia del aprovechamiento de las riquezas de países en desarrollo el cual no es compensado como debería. Sumado a esto, el uso desproporcionado de los espacios y servicios ambientales generando altos impactos y violando los derechos a otros. Para esto se desarrolla el tema de 
intercambio ecológicamente desigual, por qué y cómo surge y posteriormente se trata de cuantificar la deuda ecológica. Sin embargo, así como menciona el autor a lo largo del libro los daños y perjuicios causados al medio ambiente son inconmensurables y muchas veces irreversibles.

Relacionando lo mencionado anteriormente con el caso de Colombia, se puede decir que este país es un buen ejemplo para mostrar la gran deuda ecológica que existe. Evidentemente, la mayoría de los conflictos socioambientales que aquí se presentan en el son la consecuencia de un mal manejo de los recursos o el resultado de satisfacer los intereses de unos cuantos. Para mencionar ejemplos precisos, el Páramo de Santurbán, el cual fue entregado a una multinacional canadiense para la extracción de oro a cambio de un $4 \%$ de regalías, el desplazamiento de muchas familias y la contaminación con mercurio de las fuentes de agua que abastecen a muchas poblaciones montaña abajo. Por su lado, el gobierno colombiano habla de reubicación e indemnización a las personas afectadas, pero para ellas no es posible cuantificar el daño causado, pues en dicho territorio han construido una vida y se han generado costumbres que representan un valor inconmensurable para ellos.

Finalmente, en el capítulo once se establece la relación entre la ecología política y la economía ecológica. Martínez Alier usa este capítulo para concluir los temas desarrollados a lo largo del libro. Además, resalta la ecología económica como un elemento determinante para la existencia de la obra el ecologismo de los pobres, en tanto que es la teoría que permite establecer la relación entre el conflicto ambiental y el económico. Por otro lado, el autor retoma el tema de la ecología política y desarrolla dos estilos de esta corriente. En primer lugar, está el que analiza a los intereses y valores de la sociedad en un contexto donde los recursos son cada vez más escasos. $\mathrm{Y}$, en segundo lugar, se encuentra un estilo que destaca el significado que tiene el medio ambiente para diferentes poblaciones desde la perspectiva de su cultura. Posteriormente, Martínez Alier hace una colección de definiciones que han sido creadas por autores de diferentes ONG y que resumen de forma global el campo de la ecología política. Por último, se concluye dos formas de poder que son las causantes de los diversos conflictos 
descritos en el libro. Primero, la capacidad de imponer una decisión sobre ciertos grupos, por ejemplo la biopiratería, el intercambio ecológicamente desigual, las luchas tóxicas, entre otros. Segundo, el poder de procedimiento; es decir, provocar el uso de un lenguaje determinado de opiniones científicas por parte de diferentes actores involucrados en los conflictos.

Evidentemente, nos encontramos en un mundo globalizado que vive en apuros por avanzar desenfrenadamente. Cuando esto ocurre, se requiere crecimiento de la economía, y por lo tanto se demandan mayores recursos, que a su vez genera mayor cantidad de desechos. Aunque actualmente se ha generado cierta conciencia sobre la insustentabilidad a la que nos estamos enfrentando, existe cierta población para quien prima el interés económico y no el ambiental. Como consecuencia se generan conflictos socioambientales, pues buscan territorios ricos en recursos naturales para su extracción y máximo aprovechamiento. Con el poder económico que estos entes tienen, logran una mala distribución de los recursos que hace que las comunidades para quienes el ambiente es base de sustento se opon- gan y generen resistencia. Es por este motivo que se debe tener en cuenta los elementos de la justicia ambiental, entre ellos, la participación, la distribución y el reconocimiento de las poblaciones, los cuales buscan favorecer los derechos de las minorías que están siendo violados por movimientos capitalistas que buscan invadir y expropiar a estas poblaciones de sus recursos ambientales esenciales para la vida propia.

A lo largo del libro, se puede ver la importancia de las representaciones sociales en la implementación de proyectos que generen repercusiones socioambientales, cuando Martínez-Alier muestra cómo las comunidades pobres se oponen a los grandes proyectos que tienen un buen rendimiento económico pero terribles impactos medioambientales. La principal razón de su oposición es porque se están quedando sin un sustento de vida. Por otro lado, las comunidades tienen costumbres que han sido pasadas de generación en generación a través de los años, lo cual genera un mayor arraigo a sus tierras. Ahora bien, al ser desplazados a causa de la expropiación del territorio, las personas se ven forzadas a cambiar su forma de vida drásticamente incluyendo sus cos- 
tumbres y creencias. Por lo tanto, para una persona que tiene un determinado estilo de vida y es forzado a realizar un cambio es de esperarse que se oponga y exijan justicia ambiental.

Un elemento común encontrado en el libro es la preocupación por los menos favorecidos por su entorno. Inicialmente, se tenía la idea de que "los pobres son demasiado pobres para ser verdes" y que el principal apoyo para las campañas para el medio ambiente venían de los países con mayor poder económico. Sin embargo, para muchas de estas poblaciones la naturaleza tiene un valor sagrado e inconmensurable, y es por esta razón que lo defienden a capa y espada. Al ser estas poblaciones tradicionales y pasar sus costumbres de generación en generación, para ellos no existe la era postmaterialista. Por estos motivos, esta es una tendencia que solo se presenta en la sociedad económicamente estable, pues al tener todos los sustentos básicos las personas se pueden concentrar en asuntos no materiales, como el medio ambiente. Sumado a esto, esta tendencia no se aplica a las comunidades pobres ya que aquel sustento de vida lo encuentran en la naturaleza, por lo tanto, es- tas personas nunca dejaran a un lado la naturaleza, base de su existencia, para concentrarse en otras cosas.

En conclusión, la obra del autor Joan Martínez Alier permite a los lectores informarse sobre la realidad de los conflictos socioambientales que se presentan actualmente. Hoy en día, prima la evolución económica sobre el cuidado del medio ambiente y en la mayoría de los casos las entidades de gran poder logran manipular los medios de comunicación para que muestren parcialmente lo que está sucediendo con las comunidades y zonas que están siendo afectas. Ahora bien, en este libro se muestra al lector que él y el resto de la sociedad tienen derecho a mostrarse en contra de proyectos que afecten su sustento de vida haciendo uso de movimientos como el ecologismo de los pobres y la justicia ambiental. 